\section{Red glass for the Pharaoh Thilo Rehren}

Glass in ancient Egypt appears to have been used as a substitute for precious stones that were not available in the country. Here the process of glass manufacture is traced through the examination of the fragmentary remains of ceramic reaction vessels and crucibles used in the production of small glass ingots.

I archaeological terms, glass is a relatively young material that was invented much later than pottery or metals; only from the beginning of the Late Bronze Age onwards do we have good evidence for its intentional and routine production. Glassmaking seems to have emerged in Mesopotamia at about 1550 , and it reached Egypt shortly afterwards. However, the use of glass differs strongly from what we know today as a mass-produced, cheap and usually colourless material for windows, drinking vessels and many more items of daily use. Egyptian glass objects are typically small, colourful and highly decorative, reserved for the highest levels of society: the pharaoh, his family and the highest priests and bureaucrats. Much of it is in the form of jewellery or small containers with very narrow openings. Typically, they have a blue body inlaid with lines of white, yellow, dark blue, black or amber. Beads are in one or more colours and were often combined with other materials to form complex necklaces or decorations (Fig. 1). Before the invention of glass, such luxury items were carved from precious stones such as turquoise, lapis lazuli, amethyst, carnelian, obsidian and amber, and inlaid in gold and silver.

No single country has mines yielding all

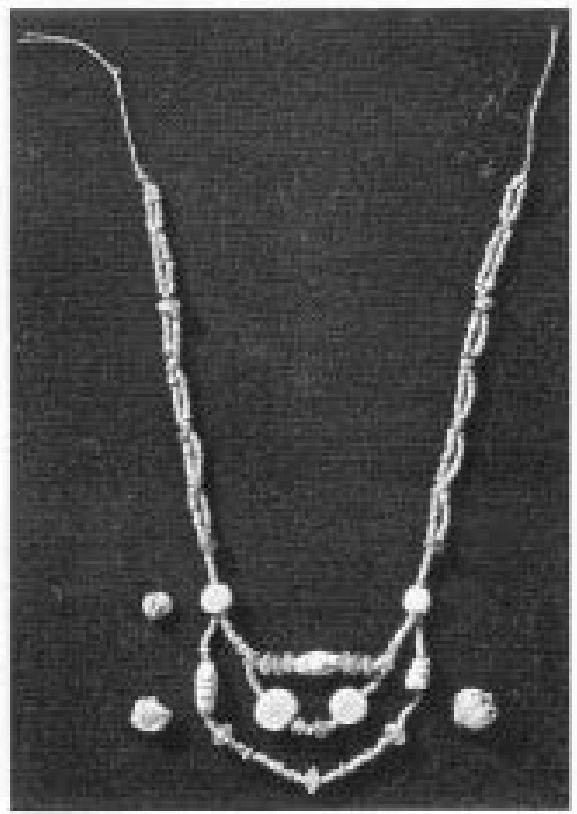

Figure 1 A necklace made from glass, faience and Egyptian blue. these precious materials, and ancient Egypt is no exception to this rule. It was famous for its riches in gold, but had no silver ores; it produced amethyst, carnelian and turquoise, but not lapis lazuli, amber or obsidian. Should the country's rulers therefore forgo their enjoyment of these other materials? There are several ways to deal with shortages of specific luxury materials. One can simply not use those not available locally; after all, they are luxury items, not necessities. One can obtain them from those who have them, by peaceful exchange, as tribute or booty, although goods to offer in return may be limited, and changing political circumstances may be disruptive. Or one can make the desired material, or materials that look quite like them. It is this latter option that interests us here, for glass in ancient Egypt is just such a material: artificially made precious stones, providing qualities and quantities of material that is otherwise difficult to obtain.

\section{Fieldwork in Egypt}

During the past six years, the Institute of Archaeology has been involved in research at Qantir, the location of the site of ancient Piramesses, in the eastern Nile Delta. The site is better known as the city of the Exodus, the new capital set up in about 1280 by Ramesses the Great in Lower Egypt. Here, Dr Edgar Pusch (the Pelizaeus Museum,

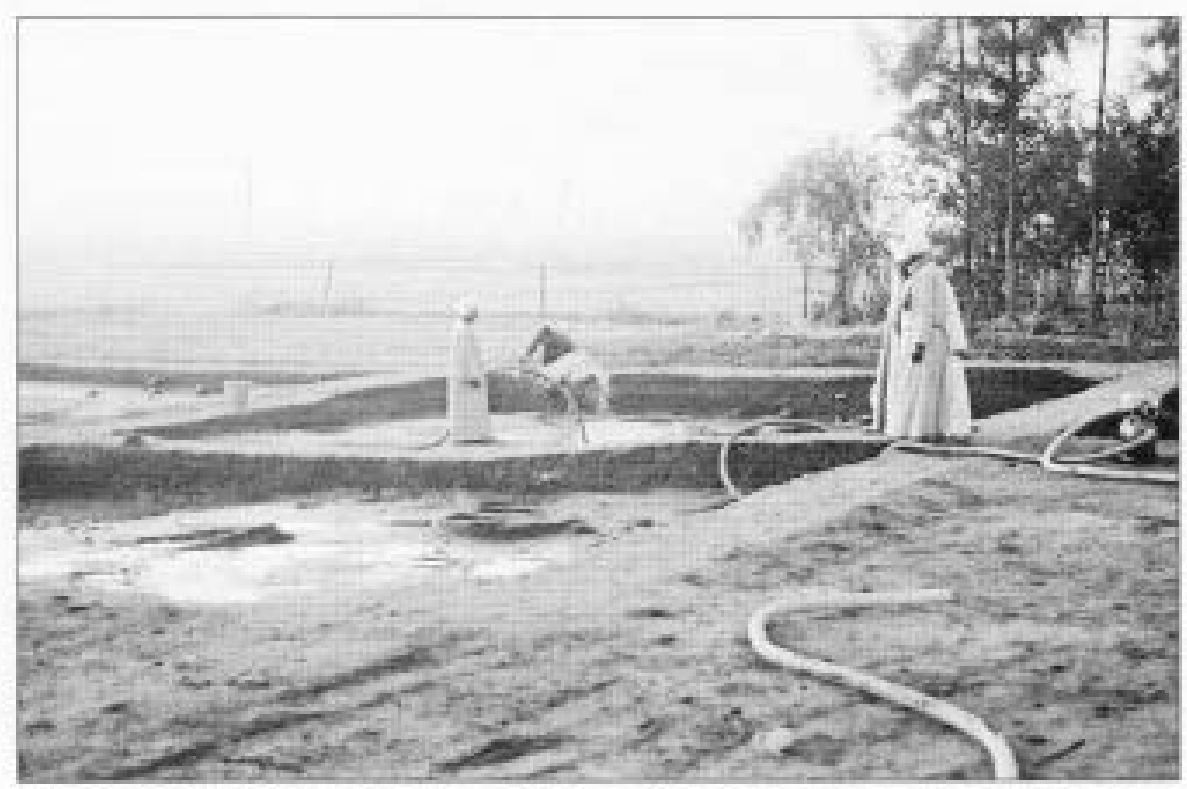

Figure 2 The shallow water table at Qantir.
Hildesheim, Germany) is excavating un industrial estate dating to the foundation period of the new city, including the largest known bronze foundries of antiquity, ${ }^{1}$ military workshops supplying and maintaining the pharaoh's chariotry including stables for hundreds of horses, and the only known production site for glass in Bronze Age Egypt and Mesopotamia. The excavations date back to the 1980s, but only in the past couple of years have we been able to identify the glassmaking evidence, although much of it had been excavated many years previously. Why this delay? Because we didn't know how to recognize glassmaking: there being no precedent or template to follow when looking for Bronze Age glassmaking, and the evidence is surprisingly unspectacular and quite different from the large-scale glassmaking remains of the end of the Roman period known from elsewhere in the Levant. Furthermore, most of the materials involved do not survive well in the wet and basic soils of the delta (Fig. 2). Only the combination of systematic long-term excavation, meticulous finds recording and painstaking investigation of unusual materials finally enabled us to piece together the evidence. ${ }^{2}$

\section{The material}

This is what we found: fragments of reaction vessels and crucibles, and severely corroded pieces of glass. The reaction vessels are identical to standardEgyptian beer jars and egg-shape storage jars (Figs 3, 4), each holding a few litres; but here, they were used to make glass from its raw materials, plant ash and crushed quartz. This initial glassmaking took place at relatively low temperatures, in the range of 900$950^{\circ} \mathrm{C}$, and resulted in an imperfect semifinished glass. Remains of the crushed quartz embedded in semi-finished glass are still attached to the interior surfaces of 


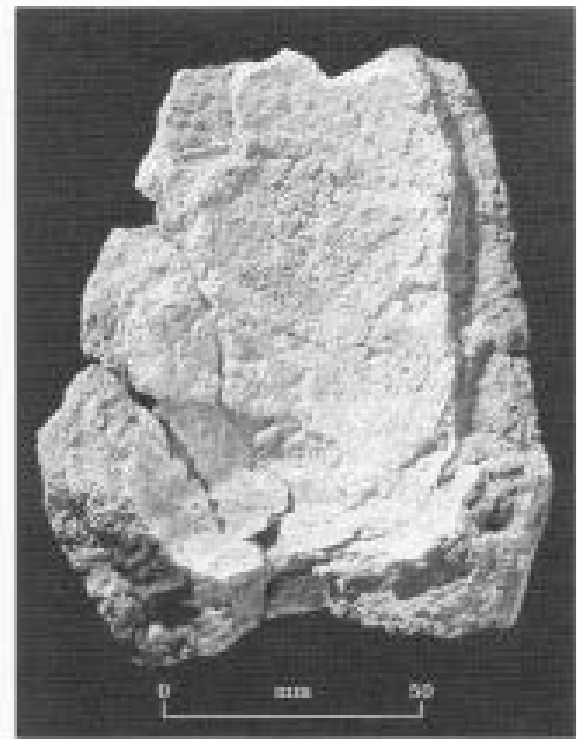

Figure 3 The bottom fragment of a reaction vessel with remains of parting layer and semi-finished glass on the inside.

some of the vessel fragments (Fig. 5), separated from the ceramic itself by a special lining made from lime to protect the vessel from reacting with its contents. This barrier or parting layer acts very much like the tin coating inside a modern tin can, which protects both the iron of the can from being

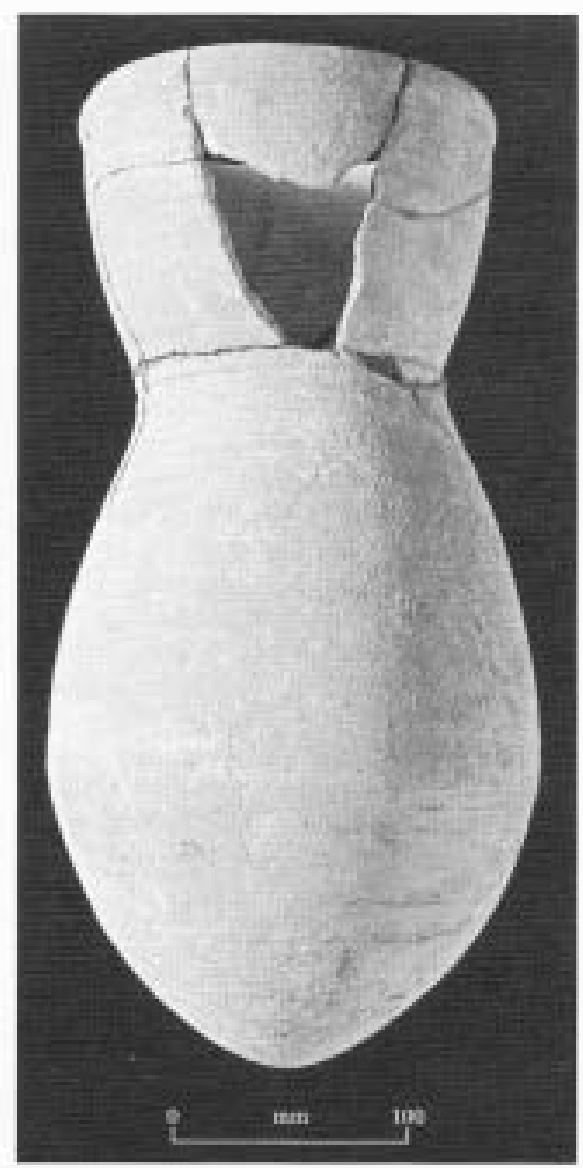

Figure 4 A typical egg-shape storage vesselof the type also used as a reaction vessel for glassmaking. corroded by the acidic contents, and the contents from being spoiled by the corroding iron. In our case, the parting layer protects the ceramic of the vessels from being attacked by the aggressive plant ash, while preventing the semi-finished glass from discolouration by the iron oxides present in the ceramic.

The second main group of finds related to glassmaking are fragments of cylindrical crucibles (Fig. 6). Crucibles are purposemade vessels used to melt metal or glass, typically at temperatures of $1000-1100^{\circ} \mathrm{C}$. In metallurgy, crucibles are often used to cast the molten metal into moulds to give it a desired shape. Glass, though, is too stiff to be cast, even at the temperatures mentioned, and is possibly best described as resembling in consistency chewing gum or toffee. Hence, these crucibles doubled up as moulds, with the molten glass cooling and solidifying inside them, producing circular discs or cakes. At this stage, metal oxides were added to give the glass the desired colour; in the case of Piramesses, a few per cent by weight of copper oxide made it a bright red. To retrieve the glass cakes, the crucibles were broken; often, small bits of glass remained stuck onto the crucible fragments, mostly in places where the lime barrier had not been thick enough to function properly. The glass cakes or ingots were the final product of the glassmaker, and were then passed on to glass studios, where artisans remelted and worked them into vases, beads and inlays.

These crucibles are much more highly fired than the reaction vessels, as can be seen from their darker colour and harder fabric. This resulted in much better preservation of the fragments, and we were able to reconstruct at least 250 individual crucibles, typically with an inner diameter of $12-18 \mathrm{~cm}$ and a height of probably about $15 \mathrm{~cm}$. Such crucibles had already been excavated more than a hundred years ago by Sir Flinders Petrie at the site of Tell el-Amarna in Middle Egypt, and tentatively linked by him to the glass and faience factories there. However, their exact function within the glassmaking process remained enigmatic until the Qantir finds were first published by us in 1997 .

A remarkable feature of the glass crucibles from Qantir is the colour of the glass associated with them. In the majority of cases there is not enough glass left, or it is too corroded to identify its original colour; however, in about 50 crucibles we see remains of bright red glass, compared to only a few with blue glass, and a single one with amethyst glass. Intriguingly, about 40 crucibles show remains of uncoloured or semi-finished glass, although this is sometimes difficult to distinguish from strongly corroded glass.

This concentration on just two colours, bright red and colourless, is remarkable in itself, as it indicates a high degree of specialization of this workshop complex. Colourless glass is very common today, but in

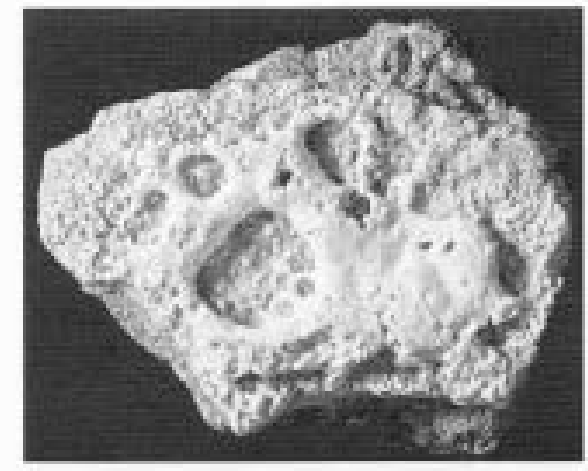

Figure 5 Semi-finished glass adhering to a fragment of a reaction vessel.

ancient Egypt it was used extremely rarely, and one might interpret its strong presence here as indicating a two-step process in which the semi-finished glass was first melted at a higher temperature to achieve a good-quality base glass, before the colorant was finally added in a second melting. If this is indeed the case, then the crucibles from Qantir would have served almost exclusively to produce glass ingots of a single colour - red. Even if we assume that only half of the crucibles actually represent a finished glass ingot, and the other half are attributable to the intermediate refining of the base glass, we still have evidence here for massive production of glass. The 250 individual crucibles alone that have been reconstructed equal more than 120 glass ingots, and even more will have been made where we have not excavated the remains.

This emphasis on red glass contrasts strongly with the colour scheme of glass objects apparent in almost every museum with Egyptian objects, where the colours are overwhelmingly dark and light blue, representing lapis lazuli and turquoise, the former being a highly prized exotic stone, and the latter deeply imbued with religious meaning and symbolism related to fertility and the goddess Hathor.

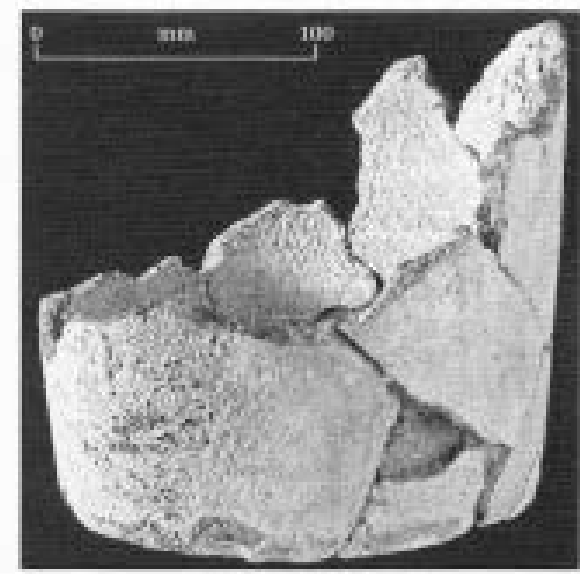

Figure 6 A reconstructed crucible from Qantir. 


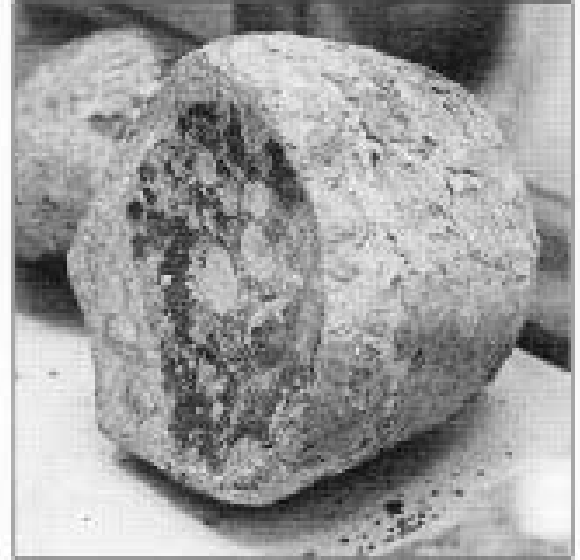

Figure 7 A glass ingot (approx. $10 \mathrm{~cm}$ thick) excavated by M. Hamza in Qantir in 1928.

\section{The products}

What about the red glass produced in such quantities at ancient Piramesses? In our excavation, only small and severely corroded fragments of glass ingots have been found, apart from a series of beads forming part of three different necklaces. However, Egyptian archaeologist Mahmout Hamza, excavating at Qantir in 1928, not only identified the site as a major faiencefactory, but also found a complete glass ingot, which is now on display in theEgyptian Museum in Luxor (Fig. 7). This ingot is superficially corroded to green, but the original bright red colour is still visible in small patches where the corrosion is flaking off. With a height of about $11 \mathrm{~cm}$ and an average diameter of about $12 \mathrm{~cm}$, it fits the typical Qantir crucible perfectly, and even though we do not have any details of its discovery or context, one may reasonably assume that it represents a typical product of the glassmaking industry at ancient Piramesses.

Although this is the only complete glass ingot known from Egypt, it is by no means the only glass ingot known from the Late Bronze Age. A few near-complete blue glass ingotsare known from several sites in Egypt and Mesopotamia, such as Lisht and Tell Brak. ${ }^{4}$ However, by far the largest number come from the wreck of a cargo ship that sank in about 1310 off the southern Turkish coast near Uluburun, and which had at least 175 glass ingots on board. ${ }^{5}$ Many of these are poorly preserved, but enough survive to identify two different colours: dark blue coloured by cobalt, probably imitating lapis lazuli, and a lighter opaque copper blue imitating turquoise. These ingots are all of the same basic disc or cake shape, relating them to the cylindrical crucibles (Fig. 6); however, the cobalt-blue ones are on averagethicker and have a somewhat larger diameter than the copper-blue ones (Fig. 8). This similarity in shape and difference in size between ingots of the two colours is interesting, and indicates that they originate from two different workshops that produced them in the same overall tradition, but using slightly different crucibles. The presence of such ingots on board a ship full with other luxury items also indicates that it was glass ingots rather than finished glass objects that were exchanged between different cultures, although at present we can only speculate as to the direction of this exchange.

\section{What is new?}

In summary, research based on the material from Qantir/Piramesses over the past ten years or so offers fascinating new insights into how one of the most beautiful materials of the Late Bronze Age was made and traded. For the first time in over a hundred years we can detail the glassmaking practice during the height of Egyptian power in the Late Bronze Age. A carefully controlled two-step process, operating first at about $900^{\circ} \mathrm{C}$ and then at about $1050^{\circ} \mathrm{C}$, prepared the colourless base glass to which colorants were finally added to produce glass cakes or ingots weighing $1.5-3.0 \mathrm{~kg}$ each. There are strong signs that different glass-production workshops were operating across Egypt and Mesopotamia, most of which were probably capable of producing light-blue glass using copper or bronze as the main colorant. However, they also appear to have specialized in the production of other particular colours, such as red in Piramesses, and elsewhere manganese purple, antimony white, lead-antimony yellow or cobalt blue. These much rarer colours required both access to exotic minerals and the knowledge of how to process them into colorants; and both the access to these minerals and the associated knowledge may have been well guarded workshop secrets. We also see evidence for a long-distance network through which the monochrome ingots were traded between different regions, so that the artists in the various glass studios near the temples and palaces of the rulers of the day had access to all the colours they needed to maketheir beautiful multicoloured objects.

Of course, further work will change and refine this picture; even within a conservative industry such as glassmaking, we would expect some technical development

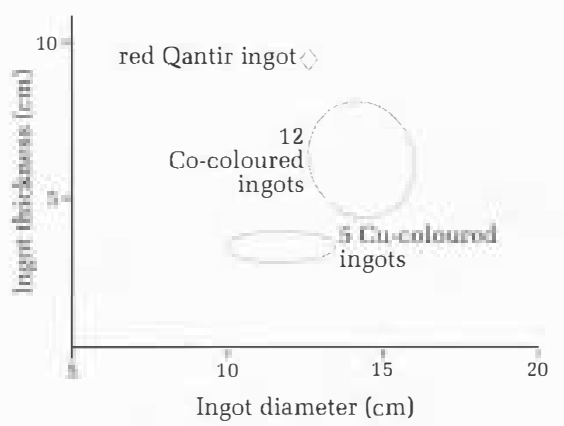

Figure 8 Comparison of ingot sizes between the blue glass ingots from the Uluburun shipwreck, five of which are coloured with copper (Cu-coloured) and twelve with cobalt (Co-coloured), and the red Qantir ingot. and adjustment to local situations and materials. However, with the basic picture sketched out, we now have a first draft from which to refine the technical reconstruction, and to improve our understanding of the organization and practicalities of this fascinating industry.

\section{Notes}

1. E. Pusch, "Metallverarbeitende Werkstätten der frühen Ramessidenzeit in QantirPiramesse-Nord", Ägypten und Levante 1, 75-113, 1990; and E. Pusch, "Piramesse", in The Oxford encyclopedia of ancient Egypt (vol. 3), D. Redford (ed.), 48-50 (Oxford: Oxford University Press, 1991).

2. Th. Rehren \& E. Pusch, "Late Bronze Age Egyptian glass production at Qantir/ Piramesses”, Science 308, 1756-59, 2005.

3. Th. Rehren, "Ramesside glass-colouring crucibles", Archaeometry 39, 355-68, 1997; and Th. Rehren \& E. Pusch "New Kingdom glass-melting crucibles from Qantir/Piramesses”, Journal of Egyptian Archaeology 83, 127-41, pl. xviii, 1997.

4. Chapter 5, "Glass, frit and faience", in Excavations at Tell Brak (vol. 1), D. Oates, J. Oates, H. MacDonald (Cambridge: McDonald Institute for Archaeological Research, 1998).

5. C. Pulak, "Das Schiffswrack von Uluburun”, in Das Schiff von Uluburun, Ü. Yalcin,C. Pulak, R. Slotta (eds), 55-102 (Bochum:Ausstellungskatalog Deutsches Bergbau-Museum, 2005). 